Sharif University of Technology
Scientia Iranica
Transactions E: Industrial Engineering
http://scientiairanica.sharif.edu
IRAENTIA

\title{
Performance evaluation in aggregate production planning using integrated RED-SWARA method under uncertain condition
}

\section{J. Khalili and A. Alinezhad*}

Department of Industrial Engineering, Faculty of Industrial and Mechanical Engineering, Qazvin Branch, Islamic Azad University, Qazvin, Iran.

Received 8 January 2018; received in revised form 8 December 2018; accepted 4 January 2020

\author{
KEYWORDS \\ Aggregate production \\ planning; \\ Performance \\ evaluation; \\ SWARA method; \\ RED model; \\ Grey system theory.
}

\begin{abstract}
Nowadays, increasing the efficiency of production and determining the proper tools and methods of measuring performance are the biggest challenges faced by managers in the context of significant competition among companies and manufacturing centers. In aggregate production planning, performance evaluation is necessary for reducing the waste of resources due to the common use of resources for product family manufacturing. The present study aims to evaluate the performance of the Aggregate Production Planning (APP). In this regard, the optimal values were determined by the multi-objective Grey Aggregate Production Planning (GAPP) model, and the weights of the input and output indicators for the performance evaluation were characterized by the Step-wise Weight Assessment Ratio Analysis (SWARA) method. Further, the efficiency of Decision-Making Units (DMUs) was determined by the Ratio Efficiency Dominance (RED) model. Then, DMUs were ranked. In the case study of the automobile parts manufacturing industry in Iran, sensitivity analysis was performed on the proposed model and its effects were evaluated. The results indicated that the proposed model had a higher degree of accuracy in evaluating performance than previous models, thus helping managers make better decisions so that the efficiency and the waste of resources can increase and decrease, respectively.

(C) 2021 Sharif University of Technology. All rights reserved.
\end{abstract}

\section{Introduction}

Production planning plays an influential role in developing and maintaining a factory. The importance of production planning in making decisions is substantially increasing, due to the rapid internationalization of jobs under globalism and the intense competition of manufacturing industries to gain an upper hand

\footnotetext{
*. Corresponding author. Tel.: +98 2833665275 ; Fax: +982833665279

E-mail addresses: Javadkhalili2@gmail.com (J. Khalili); alinezhad@qiau.ac.ir (A. Alinezhad)
}

doi: $10.24200 /$ sci.2020.50202.1584 in global markets. Production planning aims to use limited resources in production processes, leading to an appropriate use of available capacities and resources by properly forecasting the raw materials, which are necessary for producing and determining the required time for production. Increasing the efficiency of production and determining the tools and methods used for measuring performance are one of the biggest challenges faced by managers, especially under increasing competition among the companies and manufacturing centers. The performance evaluation in production planning can help each organization solve problems, find defects, and reduce delayed orders, inventory surplus, and additional production costs that are imposed on the organization, making the organization maximize 
the profit and sell the products. It is widely felt that the performance evaluation in production planning provides a theoretical and practical overview since it is a key to success and has a critical role in industries.

An Aggregate Production Planning (APP) is an activity done to determine an aggregate plan for production systems within the time period of 3-18 months so that the total cost is minimized [1] and the optimal production, labor, and inventory level are determined for each planning period in the form of product family production based on the available sources of production and restrictions. Figure 1 indicates inputs and outputs of the APP process [2].

Given that planning is conducted at a general level and is used to represent demand and production capacity from a single unit of the product family, the performance evaluation in the APP is of significance while reducing the waste of common resources. In previous studies, performance evaluation was less considered in production planning and few studies have focused on it in the field of production planning [35]. Data Envelopment Analysis (DEA) is an approach to estimating the relative efficiency of Decision-Making Units (DMUs) [6]. DEA is also regarded as a powerful mathematical tool used for measuring the relative efficiency of DMUs that utilize inputs to produce outputs [7] and is a nonparametric approach that does not require any assumption about the functional form of production [8]. Further, in DEA models, the effect of experts' opinions is taken into account to ensure the accuracy of the results. In this paper, the MultiAttribute Decision Making (MADM) method, as the effect of experts' opinions, is used for weighting the input and output indicators of the DEA model. The MADM models are selector models that are used for evaluating, ranking, and choosing the most appropriate alternative among other alternatives [9].

The present study aimed to evaluate the performance of APP using the integrated method of

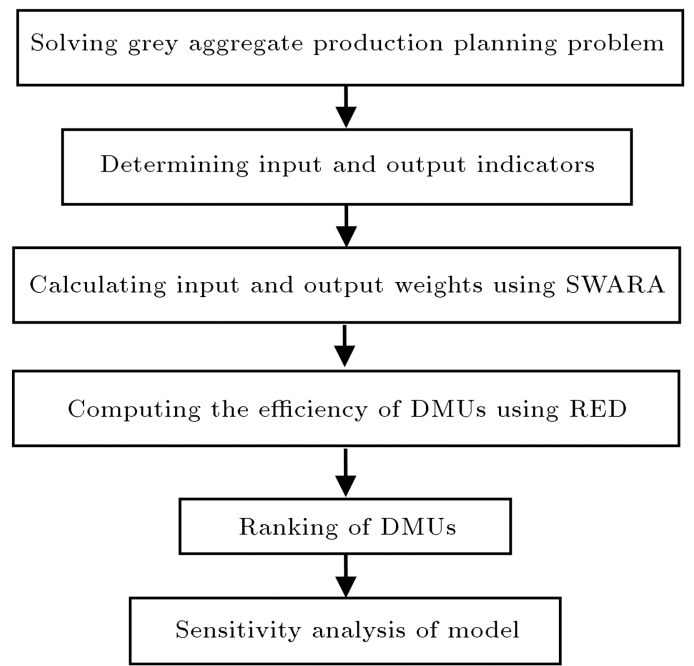

Figure 2. Proposed algorithm of the study.

Ratio Efficiency Dominance (RED) and the Step-wise Weight Assessment Ratio Analysis (SWARA) under uncertainty (grey environment). The results of the previous studies indicate that uncertainty in production planning plays a significant role in ordering policies and inventory levels [10]. The proposed model was investigated in the form of a case study in Iran automobile parts manufacturing industry during three months and accordingly, sensitivity analysis was performed on the model.

The study is organized as follows: Sections 2, 3 , and 4 include related literature, methodology, and experiment and results, respectively. Finally, Section 5 concludes the study. In addition, Figure 2 shows the proposed algorithm of this study.

\section{Literature review}

A few studies have focused on the performance evaluation in production planning. In previous studies,

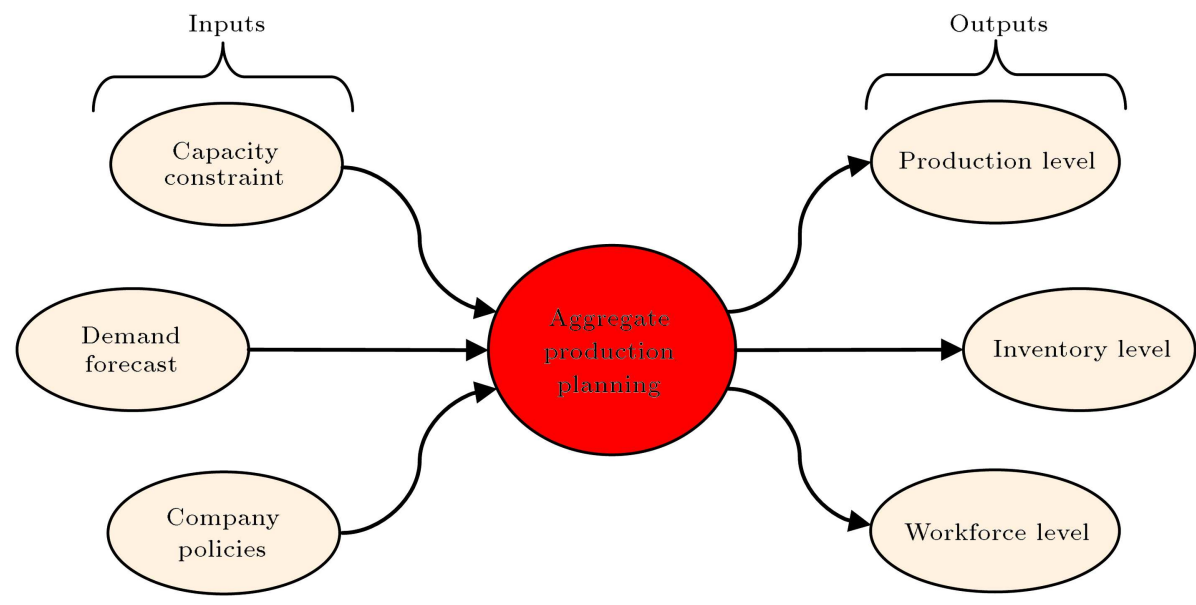

Figure 1. Inputs and outputs of Aggregate Production Planning (APP) process [2]. 
performance evaluation has been insignificantly applied in production planning, and few studies have focused on the development of the CCR model (proposed by Charnes, Cooper, and Rhodes) from DEA models [3] for evaluating efficiency or performance in a centralized decision-making environment and predictable conditions of demand variations [4], as well as for discussing cellular manufacturing [5].

Many studies have been conducted on the APP in uncertainty environment. Tang et al. [11] proposed the multi-product APP model with fuzzy demands and fuzzy capacities, and the objective of their considered problem was to minimize the total costs of quadratic production and linear inventory holding. Moreover, an interactive Multiple Fuzzy Objective Linear Programming (MFOLP) model was presented to minimize the total production costs, carrying and backordering costs, and costs of changes in labor levels while considering the inventory levels, labor levels, machine capacity, warehouse space, and time value of money [12]. Multi-product APP problems with fuzzy demands and fuzzy capacities were formulated and simulated for further analysis [13]. Having considered the need for a general joint strategic plan for production and distribution and also vague planning data, Aliev et al. [14] suggested a fuzzy-integrated multi-period and multi-product production and distribution model in the supply chain. Jamalnia and Soukhakian [15] used the Hybrid (including qualitative and quantitative objectives) Fuzzy Multi-Objective Non-Linear Programming (H-FMONLP) model for minimizing the total production costs, carrying and back ordering costs, and costs of changes in workforce level (quantitative objectives), and maximizing total customer satisfaction (qualitative objective) with regard to the inventory level, demand, labor level, machine capacity, and warehouse space.

Furthermore, Yaghin et al. [16] proposed a hybrid fuzzy multi-objective programming model that comprised both quantitative and qualitative constraints and objectives to maximize the total profit of manufacturers, total profit of retailers, and improve service aspects of retailing simultaneously. Sadeghi et al. [17] suggested a multi-objective model for aggregate planning problem in which the parameters of the model were expressed in the form of grey numbers. This grey multi-objective model was solved based on a goal programming problem with fuzzy aspiration levels. Moreover, their presented model features the Fuzzy Multi-Objective Mixed-Integer Non-Linear Programming (FMOMINLP) with four conflicting objectives: (i) to minimize the total cost, (ii) to improve customer satisfaction, (iii) to minimize the fluctuations in workforce changes, and (iv) to maximize the total value of purchasing in order to consider the impact of qualitative performance criteria [18]. Mosadegh et al. [19] applied a fuzzy goal programming model with four criteria: shortage and inventory, overtime and idle time, labor level, and currency saving in a mid-term planning horizon.

In previous studies, the combined models of MADM and DEA were used. Opricovic and Tzeng [20] presented the DEA/VIKOR method and examined the results. Raju and Kumar [21] compared two integrated DEA/EXPROM and DEA/PROMETHEE methods. Xiong [22] proposed an entropy/DEA model and evaluated the effectiveness of industrial pollution control in terms of both inputs and outputs, namely input-entropy DEA model and output-entropy DEA model. He also discussed such issues as model solving, identification of effective DMUs, and improvement of non-effective DMUs. Shakouri et al. [23] employed the DEA/SAW method to compare the same fossil fuel (coal) power plants with nuclear power plants. Moreover, one can refer to the supplier selection by using the DEA/ANP method [24] and introducing the active companies in the cement industry accepted in Tehran stock market by using DEA/TOPSIS method [25].

\section{Methodology}

The present study aims to evaluate the performance of the APP in uncertain conditions. In this regard, the optimal values of decision variables were determined using a multi-objective Grey Aggregate Production Planning (GAPP). The weights of indicators were determined using the SWARA method after identifying the input and output criteria for efficiency evaluation. Then, the efficiency of DMUs was characterized using the RED model and DMUs were ranked next.

\subsection{Grey Aggregate Production Planning $(G A P P)$}

In the APP problems, different models were used such as transportation models, simulation models, multiobjective linear programming models, and the goal programming [26]. In the present study, the multiobjective linear programming model was employed to determine the optimal values with objective functions of maximizing the utilization rate of machine capacity and total profit as well as of minimizing the cost of reworking defective products in the grey environment. The multi-objective linear programming models have appropriate flexibility and extensibility capabilities and various objective functions can be defined in this regard [27]. Furthermore, the use of grey theory plays an influential role in the flexibility of the APP model. On the contrary, the uncertainty of the model could be a better representation of real-world issues than definitive models.

In this model, the collateral contract is not allowed and the level of labor, machine capacity, warehouse capacity, and number of delayed orders should 
not exceed its maximum. Sadeghi et al. [17] considered the values of decision variables as the grey numbers. This research considers the values of decision variables as grey numbers. Further, the production planning horizon is based on performance in three months. In the following, the GAPP model is presented.

\subsubsection{Notations}

- Indices

$n$ : The index of the product

$t$ : The index of the planning period

- Decision variables

$\otimes Q_{n t}$ : $\quad$ Production of the $n$th product in period $t$ in regular time (unit)

$\otimes O_{n t}: \quad$ Production of the $n$th product in period $t$ in overtime (unit)

$\otimes I_{n t}: \quad$ Inventory level for the $n$th product in period $t$ (unit)

$\otimes B_{n t}$ : $\quad$ Backorder level for the $n$th product in period $t$ (unit)

$\otimes H_{t}: \quad$ Workers hired in period $t$ (man-hour)

$\otimes F_{t}: \quad$ Laid-off workers in period $t$ (man-hour)

- Parameters

$\otimes D_{n t}: \quad$ Forecasted demand for the $n$th product in period $t$ (unit)

$\otimes a_{n t}: \quad$ Production cost per unit for the $n$th product in period $t$ in regular time (IRR*/unit)

$\otimes b_{n t}: \quad$ Production cost per unit for the $n$th product in period $t$ (IRR/unit)

$\otimes c_{n t}$ : $\quad$ Unit revenue for the $n$th product in period $t$ (IRR/unit)

$\otimes d_{n t}: \quad$ Inventory carrying cost per unit of the $n$th product in period $t$ (IRR/unit)

$\otimes e_{n t}: \quad$ Backorder cost per unit of the $n$th product in period $t$ (IRR/unit)

$\otimes k_{t}$ : $\quad$ Cost of hiring workers in period $t$ (IRR/man-hour)

$\otimes m_{t}: \quad$ Cost of laying off one worker in period $t$ (IRR/man-hour)

$\otimes L_{n t}: \quad$ Hours of labor per unit of the $n$th product in period $t$ (man-hour/unit)

$\otimes r_{n t}: \quad$ Hours of machine usage per unit of the $n$th product in period $t$ (machine-hour per unit)

$\otimes v_{n t}: \quad$ Warehouse space per unit of the $n$th product in period $t$ (in square meter per unit)

$\otimes q_{n t}: \quad$ Defect rate of the $n$th product in period $t$ at regular time $\otimes p_{n t}: \quad$ Defect rate of the $n$th product in period $t$ in overtime

$\otimes u_{n t}: \quad$ Repairing cost of the $n$th product in period $t$ in regular time (IRR/unit)

$\otimes h_{n t}: \quad$ Repairing cost of the $n$th product in period $t$ in overtime (IRR/unit)

$\otimes W_{t \max }: \quad$ Maximum labor level available in period $t$ (man-hour)

$\otimes M_{t \max }: \quad$ Maximum machine capacity available in period $t$ (machine-hour)

$\otimes V_{t \max }: \quad$ Maximum warehouse space available in period $t$ (in square meter)

$\otimes I_{n t \text { min }}$ : Minimum inventory level available of the $n$th product in period $t$ (unit)

$\otimes B_{n t \text { max }}$ : Maximum backorder level available of the $n$th product in period $t$ (unit)

\subsubsection{Functions}

The proposed model is characterized by three objective functions as follows:

- The total profit:

$$
\begin{aligned}
\max z_{1} & \cong \sum_{n=1}^{N} \sum_{t=1}^{T} \otimes c_{n t}\left(\otimes Q_{n t}+\otimes O_{n t}\right) \\
& -\sum_{n=1}^{N} \sum_{t=1}^{T}\left(\otimes a_{n t} \cdot \otimes Q_{n t}+\otimes b_{n t} \cdot \otimes O_{n t}\right) \\
& -\sum_{n=1}^{N} \sum_{t=1}^{T}\left(\otimes d_{n t} \cdot \otimes I_{n t}+\otimes e_{n t} \cdot \otimes B_{n t}\right) \\
& -\sum_{t=1}^{T}\left(\otimes k_{t} \cdot \otimes H_{t}+\otimes m_{t} \cdot \otimes F_{t}\right) .
\end{aligned}
$$

- The cost of reworking defective products:

$$
\begin{aligned}
\min z_{2} & \cong \sum_{n=1}^{N} \sum_{t=1}^{T} \sqrt[t]{\frac{\otimes q_{n t}}{t}} \cdot \otimes u_{n t} \cdot \otimes Q_{n t} \\
+ & \sum_{n=1}^{N} \sum_{t=1}^{T} \sqrt[t]{\frac{\otimes p_{n t}}{t}} \cdot \otimes h_{n t} \cdot \otimes O_{n t} .
\end{aligned}
$$

- The utilization rate of machine capacity:

$$
\max z_{3} \cong \sum_{n=1}^{N} \sum_{t=1}^{T} \otimes r_{n t}\left(\otimes Q_{n t}+\otimes O_{n t}\right) .
$$

The proposed model has three objective functions. Therefore, Eq. (1) is related to the total profit of production, and Eq. (2) minimizes the cost of reworking defective products in regular time and 
overtime. In the current situation, the utilization rate of machine capacity is quite low and companies are interested in increasing this level [28]. Therefore, Eq. (3) specifies the utilization rate of machine capacity.

\subsubsection{Constraints}

- Constraints on carrying inventory:

$$
\begin{aligned}
& \otimes I_{n t}-\otimes B_{n t}=\otimes I_{n t-1}-\otimes B_{n t-1}+\otimes Q_{n t}+\otimes O_{n t} \\
& -\otimes D_{n t} ; \quad \forall n, t \\
& \otimes I_{n t} \geq \otimes I_{n t \text { min }} ; \quad \forall n, t \\
& \otimes B_{n t} \leq \otimes B_{n t \text { max }} ; \quad \forall n, t
\end{aligned}
$$

- Constraints on labor levels:

$$
\begin{gathered}
\sum_{n=1}^{N} \otimes L_{n t-1}\left(\otimes Q_{n t-1}+\otimes O_{n t-1}\right)+\otimes H_{t}-\otimes F_{t} \\
\quad=\sum_{n=1}^{N} \otimes L_{n t}\left(\otimes Q_{n t}+\otimes O_{n t}\right) ; \quad \forall t, \\
\sum_{n=1}^{N} \otimes L_{n t}\left(\otimes Q_{n t}+\otimes O_{n t}\right) \leq \otimes W_{\text {tmax }} ; \quad \forall t
\end{gathered}
$$

- Constraints on machine capacity and warehouse:

$$
\begin{aligned}
& \sum_{n=1}^{N} \otimes r_{n t}\left(\otimes Q_{n t}+\otimes O_{n t}\right) \leq \otimes M_{\text {tmax }} ; \quad \forall t \\
& \sum_{n=1}^{N} \otimes v_{n t} . \otimes I_{n t} \leq \otimes V_{\text {tmax }} ; \quad \forall t .
\end{aligned}
$$

- Non-negativity constraints on decision variables:

$$
\begin{aligned}
& \otimes Q_{n t}, \otimes O_{n t}, \otimes I_{n t}, \otimes B_{n t}, \otimes H_{t}, \otimes F_{t} \geq 0 ; \\
& \forall n=1, \ldots, N, \\
& \forall t=1, \ldots, T .
\end{aligned}
$$

\subsection{Step-wise Weight Assessment Ratio Analysis ( $S W A R A)$}

The Step-wise Weight Assessment Ratio Analysis (SWARA) method as one of the new MADM methods was developed by Kersuliene, Zavadskas, and Turskis in 2010. The relative importance value $\left(S_{j}\right)$ is regarded as the input of SWARA method provided by decisionmakers. The SWARA method has 4 steps [29]:

Step 1: Initially, indicators are prioritized. Beginning with the second attribute, the relative importance indicates the $j$ th attribute in relation to the previous attribute $(j-1)$, and this process is conducted for each attribute. This ratio is called "average relative importance" $\left(S_{j}\right)$ [29].
Step 2: The coefficient $K_{j}$ is determined through Eq. (12):

$$
K_{j}=\left\{\begin{array}{ll}
1 & j=1 \\
S_{j}+1 & j>1
\end{array} \quad j=1, \ldots, n\right.
$$

Step 3: The recalculated weight is determined using Eq. (13):

$$
q_{j}=\left\{\begin{array}{ll}
1 & j=1 \\
\frac{q_{j}}{K_{j}} & j>1
\end{array} j=1, \ldots, n\right.
$$

1. Step 4: The weights of attributes are calculated through Eq. (14):

$$
W_{j}=\frac{q_{j}}{\sum_{j=1}^{n} q_{j}} ; \quad j=1, \ldots, n .
$$

\subsection{Ratio Efficiency Dominance (RED)}

The Ratio Efficiency Dominance (RED) model was developed by Farahmand and Desa in 2017. Speed is of significance in computing mainly due to the large amount of information and number of DMUs. Time of computation was obtained for dual and primal simplex in 36 and $136 \mathrm{~h}$ for 100,000 DMUs, respectively [30]. This model is useful and practical for calculating and determining the efficiency of DMUs in small, large, and very large problems in the shortest time, and this model can rank the DMUs completely. The RED model includes 5 steps [30]:

Step 1: At this stage, the weighted normalized values of inputs and outputs are, respectively, calculated through Eqs. (15) and (16):

$$
\begin{aligned}
& \omega_{i j}=\mu_{i j} . w_{i j} ; i=1, \ldots, m, r=1, \ldots, s, \\
& j=1, \ldots, n, \\
& \omega_{r j}=\mu_{r j} . w_{r j}^{\prime} ; i=1, \ldots, m, r=1, \ldots, s, \\
& j=1, \ldots, n,
\end{aligned}
$$

based on the weight of the input indicators and the output indicators $w_{r j}^{\prime}$, which is determined by the SWARA method as well as the normalized weight feature of the input and output indicators. In Eqs. (15) and (16), the normalized values for the inputs $\left(\mu_{r j}\right)$ and outputs $\left(\mu_{r j}\right)$ are computed through Eqs. (17) and (18) for each DMU:

$$
\begin{aligned}
& \mu_{i j}=\frac{x_{i j}}{\max _{j}\left\{x_{i j}\right\}} ; i=1, \ldots, m, r=1, \ldots, s, \\
& j=1, \ldots, n
\end{aligned}
$$




$$
\begin{aligned}
& \mu_{r j}=\frac{y_{r j}}{\max _{j}\left\{y_{r j}\right\}} ; i=1, \ldots, m, r=1, \ldots, s, \\
& j=1, \ldots, n .
\end{aligned}
$$

Step 2: The relative score of $\mathrm{DMU}_{j}$ is calculated through Eq. (19):

$$
\begin{aligned}
& S O D I_{j}^{*}=\sum_{i=1}^{m} \sum_{r=1}^{s} \frac{\omega_{r j}}{\omega_{i j}} ; i=1, \ldots, m, r=1, \ldots, s \\
& j=1, \ldots, n .
\end{aligned}
$$

Step 3: The maximum relative score is calculated in Eq. (20):

$$
S O D I^{+}=\max _{j}\left(S O D I_{j}^{*}\right) ; j=1, \ldots, n .
$$

Step 4: The efficiency $\left(\mathrm{SODI}^{-}\right)$of $\mathrm{DMU}_{j}$ is determined through Eq. (21):

$$
S O D I_{j}^{-}=\theta S_{j}=\frac{S O D I_{j}^{*}}{S O D I^{+}} ; j=1, \ldots, n .
$$

Step 5: In order to rank the DMUs, the efficiency level (SODI ${ }^{-}$) is arranged in a descending order and then, the complete and final ranking of DMUs is made. The DMU with value 1 is determined as the most efficient DMU.

\section{Experiment and results}

\subsection{Data collection}

In this section, the production efficiency of 24 families of automobile parts was examined in the automobile parts manufacturing industry in Iran. In the present study, the mid-term and three-month planning horizons and the cost of hiring and laying-off of labor force were equal to [42300, 52900] and [50800,63400], respectively, and the initial inventory was zero. Tables 1 and 2 indicate the values of the other input parameters of the GAPP model from June to August 2017.

The three-objective (GAPP) model was converted to a single-objective model using the integrated method of LP-Metric and weighing method. Then, the optimal values of the GAPP model were coded on GAMS 24.8.3 and solved by CPLEX solver on a PC featuring 1.86 $\mathrm{GHz}$ processor and $2 \mathrm{G}$ of RAM.

\subsection{Results}

The optimal grey values of the objective functions of the total profit $\left(Z_{1}\right)$, cost of reworking defective products $\left(Z_{2}\right)$, and utilization rate of machine capacity $\left(Z_{3}\right)$ are presented in Table 3 . According to the experts' opinions, five input indicators of the forecasted demand $\left(I_{1}\right)$, maximum machine capacity $\left(I_{2}\right)$, maximum backorder level $\left(I_{3}\right)$, maximum labor level $\left(I_{4}\right)$,

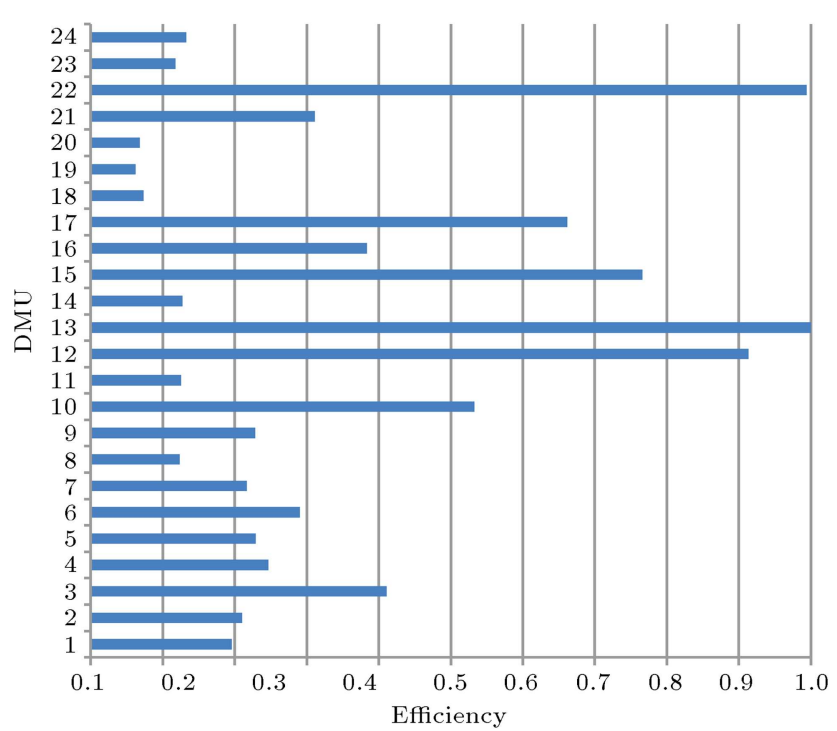

Figure 3. The final ranking of Decision-Making Units (DMUs).

and minimum inventory level $\left(I_{5}\right)$ were investigated on the DMUs; and the three output indicators of the total profit $\left(O_{1}\right)$, utilization rate of machine capacity $\left(\mathrm{O}_{2}\right)$, and cost of reworking defective products $\left(\mathrm{O}_{3}\right)$ were determined for performance evaluation as output indicators. Then, by whitenizing the grey values of the input and output, the crisp values of the inputs and outputs are shown in Table 4. Further, Tables 5 and 6 display the weights of input and output indicators determined based on SWARA method.

Finally, the efficiency values and ranks of DMUs (product families) are given in Table 7 . In addition, Figure 3 clearly shows the final ranking of DMUs.

\subsection{Sensitivity analysis}

According to the experts' opinions, five input indicators including the forecasted demand $\left(I_{1}\right)$, maximum machine capacity $\left(I_{2}\right)$, maximum backorder level $\left(I_{3}\right)$, maximum labor level $\left(I_{4}\right)$, and minimum inventory level $\left(I_{5}\right)$, as well as three output indicators including the total profit $\left(O_{1}\right)$, utilization rate of machine capacity $\left(\mathrm{O}_{2}\right)$, and cost of reworking defective products $\left(\mathrm{O}_{3}\right)$ were selected based on the importance ranking, respectively. Then, sensitivity analysis was evaluated in two scenarios.

Scenario 1: The sensitivity analysis was applied to the input indicators to determine the extent of changes in output indicators, which were the optimal values of the GAPP model objective functions. For example, the effects of decreasing and increasing each input indicator on the output indicators of the DMU 22 are shown in Table 8, considering the steady state of the other input indicators.

As observed in Table 8, the decrease and increase in the forecasted demand $\left(I_{1}\right)$, maximum backorder 
Table 1. The main information of the Grey Aggregate Production Planning (GAPP) problem.

\begin{tabular}{|c|c|c|c|c|c|c|}
\hline Family no. & Part no. & $D_{n t}$ & $a_{n t}$ & $b_{n t}$ & $c_{n t}$ & $d_{n t}$ \\
\hline \multirow[t]{4}{*}{1} & 1 & {$[20000,24000]$} & {$[12000,15000]$} & {$[18000,22000]$} & {$[40000,50000]$} & {$[2000,2500]$} \\
\hline & 2 & {$[20000,24000]$} & {$[9000,12000]$} & {$[13000,18000]$} & {$[30000,40000]$} & {$[1500,2000]$} \\
\hline & 3 & {$[20000,24000]$} & {$[6000,9000]$} & {$[9000,13000]$} & {$[20000,30000]$} & {$[1000,1500]$} \\
\hline & 4 & {$[20000,24000]$} & {$[42000,48000]$} & {$[63000,72000]$} & {$[140000,160000]$} & {$[7000,8000]$} \\
\hline \multirow[t]{3}{*}{2} & 1 & {$[20000,24000]$} & {$[12000,15000]$} & {$[18000,22000]$} & {$[40000,50000]$} & {$[2000,2500]$} \\
\hline & 2 & {$[20000,24000]$} & {$[9000,12000]$} & {$[13000,18000]$} & {$[30000,40000]$} & {$[1500,2000]$} \\
\hline & 3 & {$[20000,24000]$} & {$[12000,15000]$} & {$[18000,22000]$} & {$[40000,50000]$} & {$[2000,2500]$} \\
\hline \multirow[t]{2}{*}{3} & 1 & {$[50000,60000]$} & {$[680000,790000]$} & {$[980000,1140000]$} & {$[1970000,2280000]$} & {$[98500,114000]$} \\
\hline & 2 & {$[50000,60000]$} & {$[560000,640000]$} & {$[810000,920000]$} & {$[1620000,1850000]$} & {$[81000,92500]$} \\
\hline \multirow[t]{2}{*}{4} & 1 & {$[20000,24000]$} & {$[29000,30000]$} & {$[45000,50000]$} & {$[85000,100000]$} & {$[4500,5000]$} \\
\hline & 2 & {$[20000,24000]$} & {$[19000,21000]$} & {$[27000,31000]$} & {$[56000,70000]$} & {$[3000,3500]$} \\
\hline \multirow[t]{2}{*}{5} & 1 & {$[80000,96000]$} & {$[100000,110000]$} & {$[155000,161000]$} & {$[340000,380000]$} & {$[17500,18000]$} \\
\hline & 2 & {$[80000,96000]$} & {$[97000,98000]$} & {$[145000,146000]$} & {$[310000,350000]$} & {$[15500,16000]$} \\
\hline \multirow[t]{2}{*}{6} & 1 & {$[20000,24000]$} & {$[350000,360000]$} & {$[530000,540000]$} & {$[1190000,1200000]$} & {$[59000,60000]$} \\
\hline & 2 & {$[20000,24000]$} & {$[290000,300000]$} & {$[440000,450000]$} & {$[990000,1000000]$} & {$[49000,50000]$} \\
\hline \multirow[t]{2}{*}{7} & 1 & {$[10000,12000]$} & {$[360000,450000]$} & {$[54000,67500]$} & {$[120000,150000]$} & {$[6000,7500]$} \\
\hline & 2 & {$[10000,12000]$} & {$[210000,270000]$} & {$[31000,40000]$} & {$[70000,90000]$} & {$[3500,4500]$} \\
\hline \multirow[t]{3}{*}{8} & 1 & {$[20000,24000]$} & {$[2500,5000]$} & {$[4000,8000]$} & {$[10000,20000]$} & {$[500,1000]$} \\
\hline & 2 & {$[20000,24000]$} & {$[500,1000]$} & {$[800,1600]$} & {$[2000,4000]$} & {$[100,200]$} \\
\hline & 3 & {$[20000,24000]$} & {$[750,1250]$} & {$[1200,2000]$} & {$[3000,5000]$} & {$[150,250]$} \\
\hline \multirow[t]{2}{*}{9} & 1 & {$[20000,24000]$} & {$[105000,108000]$} & {$[157000,160000]$} & {$[350000,360000]$} & {$[35000,36000]$} \\
\hline & 2 & {$[20000,24000]$} & {$[40000,45000]$} & {$[63000,67000]$} & {$[140000,150000]$} & {$[14000,15000]$} \\
\hline \multirow[t]{2}{*}{10} & 1 & {$[20000,24000]$} & {$[130000,140000]$} & {$[190000,200000]$} & {$[380000,400000]$} & {$[19000,20000]$} \\
\hline & 2 & {$[20000,24000]$} & {$[140000,150000]$} & {$[200000,215000]$} & {$[400000,430000]$} & {$[20000,21500]$} \\
\hline \multirow[t]{2}{*}{11} & 1 & {$[40000,48000]$} & {$[24000,27000]$} & {$[36000,40000]$} & {$[80000,90000]$} & {$[4000,4500]$} \\
\hline & 2 & {$[40000,48000]$} & {$[30000,33000]$} & {$[45000,49000]$} & {$[100000,110000]$} & {$[5000,5500]$} \\
\hline \multirow[t]{2}{*}{12} & 1 & {$[10000,12000]$} & {$[75000,80000]$} & {$[112000,120000]$} & {$[250000,270000]$} & {$[12500,13500]$} \\
\hline & 2 & {$[10000,12000]$} & {$[1170000,1200000]$} & {$[1775000,1800000]$} & {$[3900000,4000000]$} & {$[195000,200000]$} \\
\hline \multirow[t]{2}{*}{13} & 1 & {$[10000,12000]$} & {$[680000,690000]$} & {$[980000,990000]$} & {$[1960000,1980000]$} & {$[196000,198000]$} \\
\hline & 2 & {$[10000,12000]$} & {$[780000,790000]$} & {$[1120000,1140000]$} & {$[2250000,2280000]$} & {$[225000,228000]$} \\
\hline \multirow[t]{2}{*}{14} & 1 & {$[20000,24000]$} & {$[50000,57000]$} & {$[80000,85000]$} & {$[180000,190000]$} & {$[90000,95000]$} \\
\hline & 2 & {$[20000,24000]$} & {$[50000,57000]$} & {$[80000,85000]$} & {$[180000,190000]$} & {$[90000,95000]$} \\
\hline \multirow[t]{2}{*}{15} & 1 & {$[10000,12000]$} & {$[52000,59000]$} & {$[75000,85000]$} & {$[150000,170000]$} & {$[7500,8500]$} \\
\hline & 2 & {$[10000,12000]$} & {$[120000,130000]$} & {$[175000,190000]$} & {$[350000,380000]$} & {$[17500,19000]$} \\
\hline \multirow[t]{2}{*}{16} & 1 & {$[10000,12000]$} & {$[73000,77000]$} & {$[105000,110000]$} & {$[210000,220000]$} & {$[10500,11000]$} \\
\hline & 2 & {$[10000,12000]$} & {$[66500,70000]$} & {$[95000,100000]$} & {$[190000,200000]$} & {$[9500,10000]$} \\
\hline \multirow[t]{2}{*}{17} & 1 & {$[20000,24000]$} & {$[1090000,1110000]$} & {$[1570000,1590000]$} & {$[3140000,3180000]$} & {$[157000,159000]$} \\
\hline & 2 & {$[20000,24000]$} & {$[847000,857000]$} & {$[1210000,1220000]$} & {$[2420000,2450000]$} & {$[121000,122500]$} \\
\hline \multirow[t]{2}{*}{18} & 1 & {$[20000,24000]$} & {$[75000,10000]$} & {$[12000,16000]$} & {$[30000,40000]$} & {$[1500,2000]$} \\
\hline & 2 & {$[20000,24000]$} & {$[12000,15000]$} & {$[20000,24000]$} & {$[50000,60000]$} & {$[2500,3000]$} \\
\hline \multirow[t]{2}{*}{19} & 1 & {$[160000,192000]$} & {$[5500,7000]$} & {$[8000,12000]$} & {$[20000,34000]$} & {$[1000,1500]$} \\
\hline & 2 & {$[160000,192000]$} & {$[3000,5000]$} & {$[4000,8000]$} & {$[10000,22000]$} & {$[500,1000]$} \\
\hline 20 & 1 & {$[10000,12000]$} & {$[10000,12000]$} & {$[16000,20000]$} & {$[40000,50000]$} & {$[2000,2500]$} \\
\hline & 2 & {$[10000,12000]$} & {$[5000,7500]$} & {$[8000,12000]$} & {$[20000,30000]$} & {$[1000,1500]$} \\
\hline 21 & 1 & {$[20000,24000]$} & {$[48000,51000]$} & {$[72000,76000]$} & {$[160000,170000]$} & {$[8000,8500]$} \\
\hline & 2 & {$[20000,24000]$} & {$[6000,9000]$} & {$[9000,13000]$} & {$[20000,30000]$} & {$[1000,1500]$} \\
\hline & 3 & {$[20000,24000]$} & {$[668000,69000]$} & {$[99000,103000]$} & {$[220000,230000]$} & {$[11000,11500]$} \\
\hline 22 & 1 & {$[10000,12000]$} & {$[1750000,1770000]$} & {$[2500000,25300000]$} & {$[5000000,5060000]$} & {$[250000,253000]$} \\
\hline & 2 & {$[10000,12000]$} & {$[1030000,1050000]$} & {$[1480000,1500000]$} & {$[2970000,3000000]$} & {$[148000,150000]$} \\
\hline 23 & 1 & {$[80000,96000]$} & {$[27000,30000]$} & {$[40000,45000]$} & {$[90000,100000]$} & {$[4500,5000]$} \\
\hline & 2 & {$[80000,96000]$} & {$[15000,18000]$} & {$[22000,27000]$} & {$[50000,60000]$} & {$[2500,3000]$} \\
\hline 24 & 1 & {$[80000,96000]$} & {$[45000,48000]$} & {$[67000,72000]$} & {$[150000,160000]$} & {$[7500,8000]$} \\
\hline & 2 & {$[80000,96000]$} & {$[45000,48000]$} & {$[67000,72000]$} & {$[150000,160000]$} & {$[7500,8000]$} \\
\hline
\end{tabular}


Table 1. The main information of the Grey Aggregate Production Planning (GAPP) problem (continued).

\begin{tabular}{|c|c|c|c|c|c|c|}
\hline Family no. & Part no. & $e_{n t}$ & $I_{n t \min }$ & $B_{n t \max }$ & $u_{n t}$ & $h_{n t}$ \\
\hline \multirow[t]{4}{*}{1} & 1 & {$[6000,7500]$} & {$[2000,2400]$} & {$[1600,1920]$} & {$[4000,5000]$} & {$[6000,7500]$} \\
\hline & 2 & {$[4500,6000]$} & {$[2000,2400]$} & {$[1600,1920]$} & {$[3000,4000]$} & {$[4000,6000]$} \\
\hline & 3 & {$[3000,4500]$} & {$[2000,2400]$} & {$[1600,1920]$} & {$[2000,3000]$} & {$[3000,4000]$} \\
\hline & 4 & {$[21000,24000]$} & {$[2000,2400]$} & {$[1600,1920]$} & {$[14000,16000]$} & {$[19000,21000]$} \\
\hline \multirow[t]{3}{*}{2} & 1 & {$[6000,7500]$} & {$[2000,2400]$} & {$[1000,1200]$} & {$[4000,5000]$} & {$[6000,8000]$} \\
\hline & 2 & {$[4500,6000]$} & {$[2000,2400]$} & {$[1000,1200]$} & {$[3000,4000]$} & {$[4000,6000]$} \\
\hline & 3 & {$[6000,7500]$} & {$[2000,2400]$} & {$[1000,1200]$} & {$[4000,5000]$} & {$[6000,8000]$} \\
\hline \multirow[t]{2}{*}{3} & 1 & {$[295000,342000]$} & {$[5000,6000]$} & {$[10000,12000]$} & {$[220000,260000]$} & {$[320000,380000]$} \\
\hline & 2 & {$[243000,277000]$} & {$[5000,6000]$} & {$[10000,12000]$} & {$[180000,210000]$} & {$[270000,300000]$} \\
\hline \multirow[t]{2}{*}{4} & 1 & {$[14000,15000]$} & {$[1000,1200]$} & {$[800,960]$} & {$[9000,10000]$} & {$[15000,16000]$} \\
\hline & 2 & {$[9000,10500]$} & {$[1000,1200]$} & {$[800,960]$} & {$[6000,7000]$} & {$[9000,10000]$} \\
\hline \multirow[t]{2}{*}{5} & 1 & {$[52000,53000]$} & {$[8000,9600]$} & {$[4000,4800]$} & {$[33500,36000]$} & {$[52000,54000]$} \\
\hline & 2 & {$[48000,49000]$} & {$[8000,9600]$} & {$[4000,4800]$} & {$[30500,33000]$} & {$[48000,50000]$} \\
\hline \multirow[t]{2}{*}{6} & 1 & {$[52000,53000]$} & {$[2000,2400]$} & {$[4000,4800]$} & {$[87000,90000]$} & {$[132000,135000]$} \\
\hline & 2 & {$[170000,180000]$} & {$[2000,2400]$} & {$[4000,4800]$} & {$[72000,75000]$} & {$[110000,112000]$} \\
\hline \multirow[t]{2}{*}{7} & 1 & {$[18000,22500]$} & {$[1000,1200]$} & {$[500,600]$} & {$[12000,19500]$} & {$[18000,25000]$} \\
\hline & 2 & {$[10000,13500]$} & {$[1000,1200]$} & {$[500,600]$} & {$[8000,13500]$} & {$[10000,16000]$} \\
\hline \multirow[t]{3}{*}{8} & 1 & {$[1500,3000]$} & {$[2000,2400]$} & {$[1000,1200]$} & {$[6000,1200]$} & {$[1000,2000]$} \\
\hline & 2 & {$[300,600]$} & {$[2000,2400]$} & {$[1000,1200]$} & {$[120,250]$} & {$[200,400]$} \\
\hline & 3 & {$[450,750]$} & {$[2000,2400]$} & {$[1000,1200]$} & {$[180,310]$} & {$[300,500]$} \\
\hline \multirow[t]{2}{*}{9} & 1 & {$[70000,72000]$} & {$[1000,1200]$} & {$[800,960]$} & {$[25000,27000]$} & {$[39000,40000]$} \\
\hline & 2 & {$[28000,30000]$} & {$[1000,1200]$} & {$[800,960]$} & {$[10000,12000]$} & {$[15000,16000]$} \\
\hline \multirow[t]{2}{*}{10} & 1 & {$[38000,40000]$} & {$[2000,2400]$} & {$[1000,1200]$} & {$[63000,66000]$} & {$[120000,130000]$} \\
\hline & 2 & {$[40000,43000]$} & {$[2000,2400]$} & {$[1000,1200]$} & {$[66000,71000]$} & {$[130000,140000]$} \\
\hline \multirow[t]{2}{*}{11} & 1 & {$[12000,13500]$} & {$[4000,4800]$} & {$[6000,7200]$} & {$[8000,9000]$} & {$[12000,13500]$} \\
\hline & 2 & {$[15000,16500]$} & {$[4000,4800]$} & {$[6000,7200]$} & {$[10000,11000]$} & {$[15000,16500]$} \\
\hline \multirow[t]{2}{*}{12} & 1 & {$[37500,40500]$} & {$[1000,1200]$} & {$[1500,1800]$} & {$[25000,27000]$} & {$[37000,40000]$} \\
\hline & 2 & {$[585000,600000]$} & {$[1000,1200]$} & {$[1500,1800]$} & {$[390000,400000]$} & {$[585000,600000]$} \\
\hline \multirow[t]{2}{*}{13} & 1 & {$[392000,396000]$} & {$[1000,1200]$} & {$[700,840]$} & {$[170000,172000]$} & {$[240000,247000]$} \\
\hline & 2 & {$[450000,456000]$} & {$[1000,1200]$} & {$[700,840]$} & {$[190000,197000]$} & {$[280000,285000]$} \\
\hline \multirow[t]{2}{*}{14} & 1 & {$[27000,285000]$} & {$[2000,2400]$} & {$[1600,1920]$} & {$[12000,14000]$} & {$[20000,21000]$} \\
\hline & 2 & {$[27000,285000]$} & {$[2000,2400]$} & {$[1600,1920]$} & {$[12000,14000]$} & {$[20000,21000]$} \\
\hline \multirow[t]{2}{*}{15} & 1 & {$[15000,17000]$} & {$[1000,1200]$} & {$[800,960]$} & {$[17000,19000]$} & {$[25000,28000]$} \\
\hline & 2 & {$[35000,38000]$} & {$[1000,1200]$} & {$[800,960]$} & {$[40000,43000]$} & {$[58000,63000]$} \\
\hline \multirow[t]{2}{*}{16} & 1 & {$[31500,33000]$} & {$[1000,1200]$} & {$[800,960]$} & {$[21000,22000]$} & {$[31000,33000]$} \\
\hline & 2 & {$[28500,30000]$} & {$[1000,1200]$} & {$[800,960]$} & {$[19000,20000]$} & {$[28000,30000]$} \\
\hline \multirow[t]{2}{*}{17} & 1 & {$[314000,318000]$} & {$[2000,2400]$} & {$[1600,1920]$} & {$[360000,370000]$} & {$[520000,530000]$} \\
\hline & 2 & {$[242000,245000]$} & {$[2000,2400]$} & {$[1600,1920]$} & {$[282000,285000]$} & {$[400000,406000]$} \\
\hline \multirow[t]{2}{*}{18} & 1 & {$[4500,6000]$} & {$[2000,2400]$} & {$[2000,2400]$} & {$[3000,4000]$} & {$[4500,6000]$} \\
\hline & 2 & {$[7500,9000]$} & {$[2000,2400]$} & {$[2000,2400]$} & {$[5000,6000]$} & {$[7500,9000]$} \\
\hline \multirow[t]{2}{*}{19} & 1 & {$[3000,4500]$} & {$[16000,19200]$} & {$[8000,9600]$} & {$[1200,1700]$} & {$[2000,3000]$} \\
\hline & 2 & {$[1500,3000]$} & {$[16000,19200]$} & {$[8000,9600]$} & {$[620,1200]$} & {$[1000,2000]$} \\
\hline 20 & 1 & {$[6000,7500]$} & {$[1000,1200]$} & {$[2000,2400]$} & {$[2500,3000]$} & {$[4000,5000]$} \\
\hline & 2 & {$[3000,4500]$} & {$[1000,1200]$} & {$[2000,2400]$} & {$[1200,1800]$} & {$[2000,3000]$} \\
\hline 21 & 1 & {$[24000,25500]$} & {$[1000,1200]$} & {$[800,960]$} & {$[12000,12700]$} & {$[18000,19000]$} \\
\hline & 2 & {$[3000,4500]$} & {$[1000,1200]$} & {$[800,960]$} & {$[1500,2200]$} & {$[2200,3200]$} \\
\hline & 3 & {$[33000,34500]$} & {$[1000,1200]$} & {$[800,960]$} & {$[16500,17200]$} & {$[24000,25700]$} \\
\hline 22 & 1 & {$[750000,759000]$} & {$[500,600]$} & {$[1000,1200]$} & {$[437000,442000]$} & {$[625000,632000]$} \\
\hline & 2 & {$[444000,450000]$} & {$[500,600]$} & {$[1000,1200]$} & {$[259000,262000]$} & {$[371000,375000]$} \\
\hline 23 & 1 & {$[13000,15000]$} & {$[8000,9600]$} & {$[6400,7680]$} & {$[14200,15000]$} & {$[21000,22500]$} \\
\hline & 2 & {$[7500,9000]$} & {$[8000,9600]$} & {$[6400,7680]$} & {$[3700,4500]$} & {$[5500,6750]$} \\
\hline 24 & 1 & {$[22500,24000]$} & {$[8000,9600]$} & {$[4000,4800]$} & {$[15000,16000]$} & {$[22000,24000]$} \\
\hline & 2 & {$[22500,24000]$} & {$[8000,9600]$} & {$[4000,4800]$} & {$[15000,16000]$} & {$[22000,24000]$} \\
\hline
\end{tabular}


Table 2. Parameter values for the Grey Aggregate Production Planning (GAPP) problem in planning horizon.

\begin{tabular}{|c|c|c|c|c|c|c|c|c|}
\hline $\begin{array}{c}\text { Family } \\
\text { no. }\end{array}$ & $p_{n t}$ & $\boldsymbol{q}_{n t}$ & $V_{t \max }$ & $M_{t \max }$ & $W_{t \max }$ & $\boldsymbol{v}_{n t}$ & $r_{n t}$ & $L_{n t}$ \\
\hline 1 & {$[0.06,0.07]$} & {$[0.06,0.07]$} & 600 & {$[8000,9000]$} & {$[10000,11000]$} & {$[0.01,0.02]$} & {$[0.06,0.07]$} & {$[0.08,0.09]$} \\
\hline 2 & {$[0.04,0.05]$} & {$[0.04,0.05]$} & 1000 & {$[9000,11000]$} & {$[13000,15000]$} & {$[0.04,0.06]$} & {$[0.09,0.11]$} & {$[0.14,0.15]$} \\
\hline 3 & {$[0.02,0.03]$} & {$[0.02,0.03]$} & 2000 & {$[21000,23000]$} & {$[24000,27000]$} & {$[0.02,0.03]$} & {$[0.14,0.15]$} & {$[0.16,0.17]$} \\
\hline 4 & {$[0.04,0.05]$} & {$[0.04,0.05]$} & 1600 & {$[7000,8000]$} & {$[10000,12000]$} & {$[0.01,0.02]$} & {$[0.07,0.09]$} & {$[0.1,0.12]$} \\
\hline 5 & {$[0.03,0.05]$} & {$[0.03,0.05]$} & 850 & {$[11000,13000]$} & {$[14000,16000]$} & {$[0.005,0.01]$} & {$[0.04,0.05]$} & {$[0.06,0.07]$} \\
\hline 6 & {$[0.02,0.03]$} & {$[0.02,0.03]$} & 2000 & {$[8000,9000]$} & {$[12000,15000]$} & {$[0.01,0.012]$} & {$[0.13,0.15]$} & {$[0.18,0.2]$} \\
\hline 7 & {$[0.04,0.05]$} & {$[0.04,0.05]$} & 700 & {$[4000,5000]$} & {$[6000,7000]$} & {$[0.01,0.02]$} & {$[0.07,0.09]$} & {$[0.09,0.11]$} \\
\hline 8 & {$[0.06,0.07]$} & {$[0.06,0.07]$} & 450 & {$[4000,6000]$} & {$[7000,9000]$} & {$[0.004,0.006]$} & {$[0.03,0.05]$} & {$[0.06,0.07]$} \\
\hline 9 & {$[0.04,0.05]$} & {$[0.04,0.05]$} & 1300 & {$[4000,5000]$} & {$[6000,7000]$} & {$[0.03,0.04]$} & {$[0.06,0.07]$} & {$[0.08,0.09]$} \\
\hline 10 & {$[0.03,0.04]$} & {$[0.03,0.04]$} & 2500 & {$[10000,12000]$} & {$[12000,14000]$} & {$[0.006,0.01]$} & {$[0.1,0.13]$} & {$[0.13,0.16]$} \\
\hline 11 & {$[0.03,0.05]$} & {$[0.03,0.05]$} & 850 & {$[10000,11000]$} & {$[13000,14000]$} & {$[0.01,0.02]$} & {$[0.07,0.08]$} & {$[0.09,0.1]$} \\
\hline 12 & {$[0.04,0.05]$} & {$[0.04,0.05]$} & 4800 & {$[14000,16000]$} & {$[18000,20000]$} & {$[0.026,0.028]$} & {$[0.14,0.15]$} & {$[0.16,0.17]$} \\
\hline 13 & {$[0.03,0.05]$} & {$[0.03,0.05]$} & 3400 & {$[10000,11000]$} & {$[13000,14000]$} & {$[0.035,0.04]$} & {$[0.15,0.18]$} & {$[0.18,0.2]$} \\
\hline 14 & {$[0.02,0.03]$} & {$[0.02,0.03]$} & 760 & {$[4000,5000]$} & {$[6000,8000]$} & {$[0.01,0.02]$} & {$[0.05,0.07]$} & {$[0.08,0.09]$} \\
\hline 15 & {$[0.03,0.04]$} & {$[0.03,0.04]$} & 2500 & {$[13000,14000]$} & {$[16000,17000]$} & {$[0.007,0.009]$} & {$[0.1,0.11]$} & {$[0.13,0.14]$} \\
\hline 16 & {$[0.03,0.04]$} & {$[0.03,0.04]$} & 2500 & {$[6000,9000]$} & {$[12000,14000]$} & {$[0.025,0.03]$} & {$[0.1,0.14]$} & {$[0.15,0.17]$} \\
\hline 17 & {$[0.03,0.04]$} & {$[0.03,0.04]$} & 2500 & {$[6000,8000]$} & {$[9000,11000]$} & {$[0.07,0.08]$} & {$[0.1,0.12]$} & {$[0.13,0.15]$} \\
\hline 18 & {$[0.06,0.07]$} & {$[0.06,0.07]$} & 600 & {$[3000,4000]$} & {$[6000,7000]$} & {$[0.03,0.04]$} & {$[0.04,0.05]$} & {$[0.07,0.08]$} \\
\hline 19 & {$[0.05,0.06]$} & {$[0.05,0.06]$} & 1300 & {$[5000,6000]$} & {$[9000,10000]$} & {$[0.003,0.005]$} & {$[0.01,0.02]$} & {$[0.03,0.04]$} \\
\hline 20 & {$[0.03,0.04]$} & {$[0.03,0.04]$} & 500 & {$[2000,3000]$} & {$[5000,6000]$} & {$[0.02,0.03]$} & {$[0.05,0.07]$} & {$[0.08,0.09]$} \\
\hline 21 & {$[0.04,0.05]$} & {$[0.04,0.05]$} & 1600 & {$[7000,8000]$} & {$[9000,10000]$} & {$[0.01,0.02]$} & {$[0.07,0.08]$} & {$[0.12,0.13]$} \\
\hline 22 & {$[0.02,0.03]$} & {$[0.02,0.03]$} & 2000 & {$[5000,6000]$} & {$[8000,10000]$} & {$[0.005,0.01]$} & {$[0.16,0.18]$} & {$[0.2,0.22]$} \\
\hline 23 & {$[0.02,0.03]$} & {$[0.02,0.03]$} & 2200 & {$[12000,14000]$} & {$[15000,17000]$} & {$[0.005,0.01]$} & {$[0.05,0.07]$} & {$[0.08,0.09]$} \\
\hline 24 & {$[0.03,0.05]$} & {$[0.03,0.05]$} & 850 & {$[10000,12000]$} & {$[12000,14000]$} & {$[0.005,0.01]$} & {$[0.04,0.05]$} & {$[0.06,0.07]$} \\
\hline
\end{tabular}

level $\left(I_{3}\right)$, and minimum inventory level $\left(I_{5}\right)$ indicators play a significant role in decreasing and increasing the effect, respectively. However, an increase and decrease in the maximum machine capacity $\left(I_{2}\right)$ and maximum labor level $\left(I_{4}\right)$ indicators did not affect the total profit $\left(O_{1}\right)$, utilization rate of machine capacity $\left(O_{2}\right)$, and cost of reworking defective products $\left(\mathrm{O}_{3}\right)$.

Scenario 2: The sensitivity analysis of the input indicators was performed in two ways to examine the variations in the efficiency of DMUs. Figure 4 shows the effects of decreasing and increasing each input indicator on DMUs with respect to the initial efficiency $(M)$ while considering the other input indicators as constant based on the decrease and increase in input indicators in Scenario 1. The error band for the indicators of $I_{1}$ equals \pm 1000 unit (Figure 4(a)), $I_{2}$ equals \pm 500 machine-hour (Figure $4(\mathrm{~b})), I_{3}$ equals \pm 1000 unit (Figure 4(c)), $I_{4}$ equals \pm 700 man-hour (Figure $4(\mathrm{~d})$ ), and $I_{5}$ equals \pm 300 unit (Figure $4(\mathrm{e})$ ).

As observed in Figure 4, a decrease and increase in the maximum machine capacity $\left(I_{2}\right)$, maximum backorder level $\left(I_{3}\right)$, and maximum labor level $\left(I_{4}\right)$ indicators play a slight role in the efficiency of DMUs. However, 
Table 3. Grey optimal values of the Grey Aggregate Production Planning (GAPP) model.

\begin{tabular}{|c|c|c|c|}
\hline Family no. & Total profit & $\begin{array}{l}\text { Cost of reworking } \\
\text { defective products }\end{array}$ & $\begin{array}{l}\text { Utilization rate of } \\
\text { machine capacity }\end{array}$ \\
\hline 1 & [8755000000, 11089562340] & {$[343994386,448588884]$} & {$[18000,20294]$} \\
\hline 2 & [3695860667, 5943411333] & {$[112856437,224857103]$} & {$[15900,25593]$} \\
\hline 3 & [230455000000, 322791000000] & {$[5135000000,11770934143]$} & {$[40600,52200]$} \\
\hline 4 & {$[7418400000,7700085156]$} & {$[118428814,294433907]$} & {$[14000,16683]$} \\
\hline 5 & [119551000000, 147719000000] & [3604416556, 4771489479] & {$[25840,32937]$} \\
\hline 6 & {$[68128796000,85659648000]$} & [1424678408, 18329471119] & {$[15080,20880]$} \\
\hline 7 & {$[6239425964,7513875822]$} & {$[182765518,187591208]$} & {$[9065,9522]$} \\
\hline 8 & {$[664178000,1889711600]$} & {$[9767912,42378661]$} & {$[8685,14370]$} \\
\hline 9 & [15167510400, 25795755120] & {$[323674560,453123172]$} & {$[7224,12221]$} \\
\hline 10 & [53617969231, 53795300000] & [2958029340, 3830374198] & {$[27692,34125]$} \\
\hline 11 & [15243237143, 19604936500] & {$[456795381,511536292]$} & {$[22330,225288]$} \\
\hline 12 & {$[86524946154,102760000000]$} & [2938103402, 3911117353] & {$[34036,36244]$} \\
\hline 13 & [101903000000, 108486000000] & [4483260180, 5583984939] & {$[17590,21930]$} \\
\hline 14 & [7636040000, 9861681133] & [200739459, 381290209] & {$[9800,10805]$} \\
\hline 15 & [29025215385, 48422818056] & {$[1008582784,1531858745]$} & {$[36923,38264]$} \\
\hline 16 & {$[16568550000,17427663095]$} & {$[525146909,653750815]$} & {$[16000,21747]$} \\
\hline 17 & {$[157124000000,192489000000]$} & {$[4890587702,7180014758]$} & {$[12080,17395]$} \\
\hline 18 & [3255773200, 4433601600] & {$[85831495,164125714]$} & {$[4832,7248]$} \\
\hline 19 & {$[8597516000,22143470400]$} & {$[182553273,473257802]$} & {$[9760,23424]$} \\
\hline 20 & [1130040000, 1506710533] & {$[6722946,24756480]$} & {$[3150,4872]$} \\
\hline 21 & {$[16396900000,17222759011]$} & {$[475872298,519664016]$} & {$[15750,17822]$} \\
\hline 22 & [109474000000, 132586000000] & [2233488733, 3336988243] & {$[9440,12744]$} \\
\hline 23 & [23437150000, 26573781991] & {$[680455870,932646997]$} & {$[28125,40589]$} \\
\hline 24 & {$[51554200000,56297860000]$} & [1411078626, 1973350581] & {$[24000,30000]$} \\
\hline
\end{tabular}

an increase and decrease in the forecasted demand $\left(I_{1}\right)$ and minimum inventory level $\left(I_{5}\right)$ indicators play a significant role in the efficiency of DMUs with respect to the initial efficiency $(M)$.

\section{Conclusion}

Increasing the production efficiency and determining the tools and methods used for measuring performance are the biggest challenges faced by managers through the increasing competition among companies and manufacturing centers. Performance evaluation in produc- tion planning can help any organization resolve the deficiencies, reduce the waste of resources, maximize the profit and sales of products, and decrease the inventory surplus and additional production costs. In other words, the performance evaluation of product planning provides a theoretical and practical overview. The present study aimed to evaluate the performance of the APP process and the proposed model was investigated in a case study related to the automobile parts manufacturing industry in Iran.

In previous studies, efficiency evaluation in production planning has not received sufficient research 
Table 4. Input and output values.

\begin{tabular}{ccccccccc}
\hline DMU & $\boldsymbol{I}_{\mathbf{1}}$ & $\boldsymbol{I}_{\mathbf{2}}$ & $\boldsymbol{I}_{\boldsymbol{3}}$ & $\boldsymbol{I}_{\boldsymbol{4}}$ & $\boldsymbol{I}_{\mathbf{5}}$ & $\boldsymbol{O}_{\mathbf{1}}$ & $\boldsymbol{O}_{\mathbf{2}}$ & $\boldsymbol{O}_{\boldsymbol{3}}$ \\
\hline DMU 1 & 22000 & 8500 & 1760 & 10500 & 2200 & 9922281170 & 19147 & 396291635 \\
DMU 2 & 22000 & 10000 & 1100 & 14000 & 2200 & 4819636000 & 20747 & 168856770 \\
DMU 3 & 55000 & 22000 & 11000 & 25500 & 5500 & 276623000000 & 46400 & 8452967072 \\
DMU 4 & 22000 & 7500 & 880 & 10000 & 1100 & 7559242578 & 15342 & 206431361 \\
DMU 5 & 88000 & 12000 & 4400 & 15000 & 8800 & 133635000000 & 29389 & 4187953018 \\
DMU 6 & 22000 & 8500 & 4400 & 13500 & 2200 & 76894222000 & 17980 & 1628812764 \\
DMU 7 & 11000 & 4500 & 550 & 6500 & 1100 & 6876650893 & 9294 & 185178363 \\
DMU 8 & 22000 & 5000 & 1100 & 8000 & 2200 & 1276944800 & 11528 & 26073287 \\
DMU 9 & 22000 & 4500 & 880 & 6500 & 1100 & 20481632760 & 9723 & 388398866 \\
DMU 10 & 22000 & 11000 & 1100 & 13000 & 2200 & 53706634616 & 30909 & 3394201769 \\
DMU 11 & 44000 & 10500 & 6600 & 13500 & 4400 & 17424086822 & 23809 & 484165837 \\
DMU 12 & 11000 & 15000 & 1650 & 19000 & 1100 & 94642473077 & 35140 & 3424610378 \\
DMU 13 & 11000 & 10500 & 770 & 13500 & 1100 & 105194500000 & 19760 & 5033622560 \\
DMU 14 & 22000 & 4500 & 1760 & 7000 & 2200 & 8748860567 & 10303 & 291014834 \\
DMU 15 & 11000 & 13500 & 880 & 16500 & 1100 & 38724016721 & 37594 & 1270220765 \\
DMU 16 & 11000 & 8500 & 880 & 13000 & 1100 & 16998106548 & 18874 & 589448862 \\
DMU 17 & 22000 & 7000 & 1760 & 10000 & 2200 & 174806500000 & 14738 & 6035301230 \\
DMU 18 & 22000 & 3500 & 1760 & 6500 & 2200 & 3844687400 & 6040 & 124978605 \\
DMU 19 & 176000 & 5500 & 8800 & 9500 & 17600 & 15370493200 & 16592 & 327905538 \\
DMU 20 & 11000 & 2500 & 2200 & 5500 & 1100 & 1318375267 & 4011 & 15739713 \\
DMU 21 & 22000 & 7500 & 880 & 9500 & 1100 & 16809829506 & 16786 & 497768157 \\
DMU 22 & 11000 & 11500 & 1100 & 14000 & 550 & 121030000000 & 11092 & 2785238488 \\
DMU 23 & 88000 & 13000 & 7040 & 16000 & 8800 & 25005465996 & 34357 & 806551434 \\
DMU 24 & 88000 & 11000 & 7040 & 13000 & 8800 & 53926030000 & 27000 & 1692214604 \\
\hline
\end{tabular}

Table 5. Weights of the input indicators.

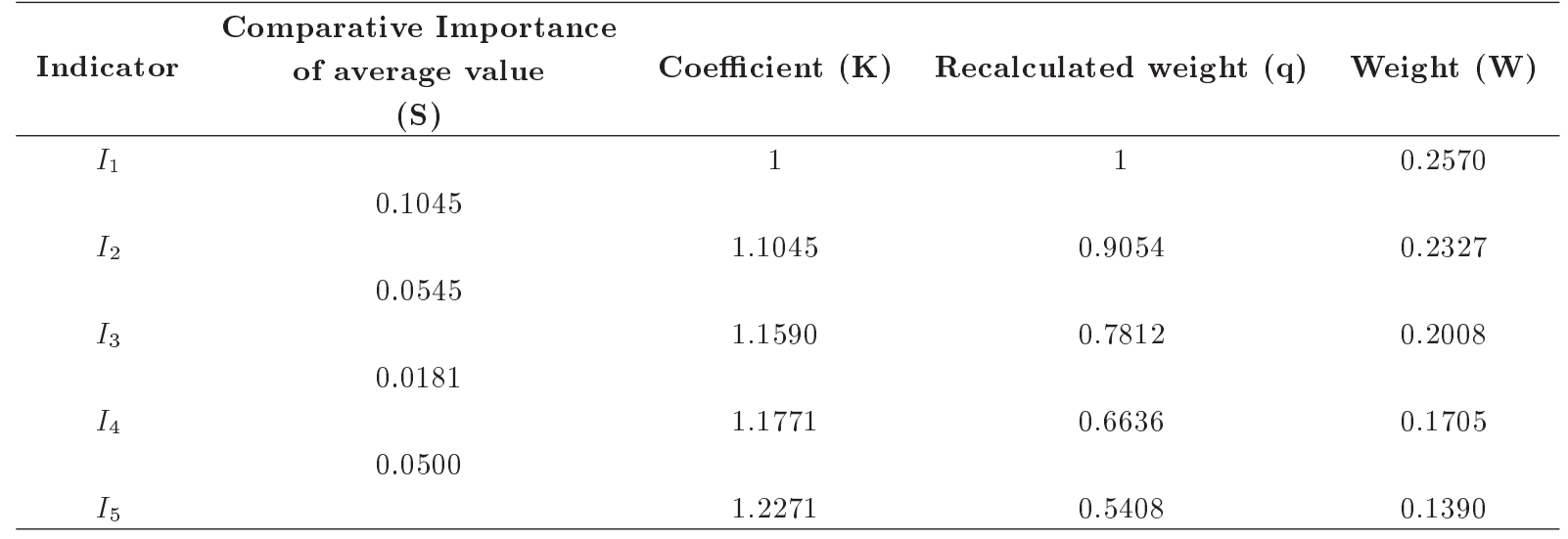

Table 6. Weights of the output indicators.

\begin{tabular}{ccccc}
\hline Indicator & $\begin{array}{c}\text { Comparative Importance } \\
\text { of average value }\end{array}$ & Coefficient (K) & Recalculated weight (q) & Weight (W) \\
\hline$O_{1}$ & 0.1000 & 1 & 1 & 0.3709 \\
$O_{2}$ & 0.0545 & 1.1000 & 0.9091 & 0.3371 \\
$O_{3}$ & & 1.1545 & 0.7874 & 0.2920 \\
\hline
\end{tabular}


Table 7. The efficiency values and rank of DMUs.

\begin{tabular}{|c|c|c|}
\hline DMU & Efficiency & Rank \\
\hline $\mathrm{DMU}_{1}$ & 0.1958 & 16 \\
\hline $\mathrm{DMU}_{2}$ & 0.2100 & 15 \\
\hline $\mathrm{DMU}_{3}$ & 0.4110 & 7 \\
\hline $\mathrm{DMU}_{4}$ & 0.2467 & 11 \\
\hline $\mathrm{DMU}_{5}$ & 0.2290 & 12 \\
\hline $\mathrm{DMU}_{6}$ & 0.2904 & 10 \\
\hline $\mathrm{DMU}_{7}$ & 0.2167 & 14 \\
\hline $\mathrm{DMU}_{8}$ & 0.1235 & 20 \\
\hline $\mathrm{DMU}_{9}$ & 0.2287 & 13 \\
\hline $\mathrm{DMU}_{10}$ & 0.5329 & 6 \\
\hline $\mathrm{DMU}_{11}$ & 0.1258 & 19 \\
\hline $\mathrm{DMU}_{12}$ & 0.9134 & 3 \\
\hline $\mathrm{DMU}_{13}$ & 1 & 1 \\
\hline $\mathrm{DMU}_{14}$ & 0.1273 & 18 \\
\hline $\mathrm{DMU}_{15}$ & 0.7660 & 4 \\
\hline $\mathrm{DMU}_{16}$ & 0.3839 & 8 \\
\hline $\mathrm{DMU}_{17}$ & 0.6621 & 5 \\
\hline $\mathrm{DMU}_{18}$ & 0.0736 & 22 \\
\hline $\mathrm{DMU}_{19}$ & 0.0622 & 24 \\
\hline $\mathrm{DMU}_{20}$ & 0.0683 & 23 \\
\hline $\mathrm{DMU}_{21}$ & 0.3110 & 9 \\
\hline $\mathrm{DMU}_{22}$ & 0.9945 & 2 \\
\hline $\mathrm{DMU}_{23}$ & 0.1176 & 21 \\
\hline $\mathrm{DMU}_{24}$ & 0.1329 & 17 \\
\hline
\end{tabular}

interest. The previous researches either focused on the performance measurement through basic DEA models such as the CCR model [3] or evaluated the performance in the planning field in a centralized decisionmaking environment and predictable conditions of demand variations [4], as well as discussed cellular manufacturing [5]. However, the algorithm used in this study, which dealt with the evaluation of performance of the APP using new methods for the first time, aimed to maximize the utilization rates of machine capacity and total profit and also, to minimize the cost of reworking defective products. Moreover, through the development of the GAPP model provided in the study conducted by Sadeghi et al. [17], the optimal values for the objective functions and input and output indicators of the DEA model (with the opinions of experts) were initially determined by identifying the objective functions. Then, the weights of the input and output indicators were added to the RED model (to increase the accuracy of performance evaluation) and the model was improved using the SWARA model, taking into account the experts' opinions. Finally, after determining the efficiency values and final ranking of DMUs (production units in the automobile parts manufacturing industry in Iran), the strengths and weaknesses associated with the performance of decision-making units were examined using sensitivity analysis in the proposed model.

The effect of variation on performance and output indicators was also evaluated by sensitivity analysis of the input indicators of the proposed model. Based on the results of the sensitivity analysis, the changes in the maximum machine capacity $\left(I_{2}\right)$, maximum backorder level $\left(I_{3}\right)$, and maximum labor level $\left(I_{4}\right)$ indicators played an insignificant role in the efficiency of DMUs, compared to those in the forecast demand $\left(I_{1}\right)$ and minimum inventory level $\left(I_{5}\right)$ indicators. Thus, according to the number of changes in and initial efficiency of each DMU, appropriate decisions should be made. For example, in the case of DMU 3, it is suggested that some changes be made including a decrease in $I_{1}$ and $I_{2}$ indices and an increase in $I_{3}, I_{4}$, and $I_{5}$ indicators to increase the efficiency of this DMU. Furthermore, the changes in the forecasted demand $\left(I_{1}\right)$, maximum backorder level $\left(I_{3}\right)$, and minimum inventory level $\left(I_{5}\right)$

Table 8. The results of sensitivity analysis of DMU 22 .

\begin{tabular}{ccccccccc}
\hline \multirow{2}{*}{ Indicator } & \multirow{2}{*}{ Target } & \multirow{2}{*}{ Changed } & \multicolumn{3}{c}{$\boldsymbol{O}_{\mathbf{1}}$} & \multicolumn{2}{c}{$\boldsymbol{O}_{\mathbf{2}}$} & \multicolumn{2}{c}{$\boldsymbol{O}_{\mathbf{3}}$} \\
\cline { 3 - 8 } & & & Target & Result & Target & Result & Target & Result \\
\hline$I_{1}$ & 11000 & 10000 & 121030000000 & 109398450000 & 11092 & 10072 & 2785238488 & 2530558528 \\
& 11000 & 12000 & 121030000000 & 132661000000 & 11092 & 12112 & 2785238488 & 3039918449 \\
$I_{2}$ & 11500 & 11000 & 121030000000 & 121030000000 & 11092 & 11092 & 2785238488 & 2785238488 \\
& 11500 & 12500 & 121030000000 & 121030000000 & 11092 & 11092 & 2785238488 & 2785238488 \\
$I_{3}$ & 1100 & 800 & 121030000000 & 123386500000 & 11092 & 11194 & 2785238488 & 2809024570 \\
& 1100 & 2100 & 121030000000 & 113175000000 & 11092 & 10752 & 2785238488 & 2705951550 \\
$I_{4}$ & 14000 & 13000 & 121030000000 & 121030000000 & 11092 & 11092 & 2785238488 & 2785238488 \\
& 14000 & 14700 & 121030000000 & 121030000000 & 11092 & 11092 & 2785238488 & 2785238488 \\
$I_{5}$ & 550 & 250 & 121030000000 & 120115500000 & 11092 & 10990 & 2785238488 & 2761452407 \\
& 550 & 1050 & 121030000000 & 122554500000 & 11092 & 11262 & 2785238488 & 2824881957 \\
\hline
\end{tabular}




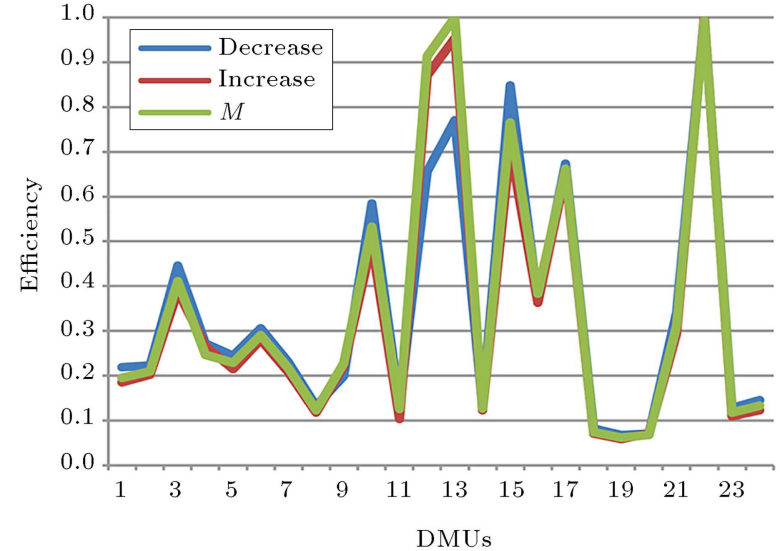

(a)

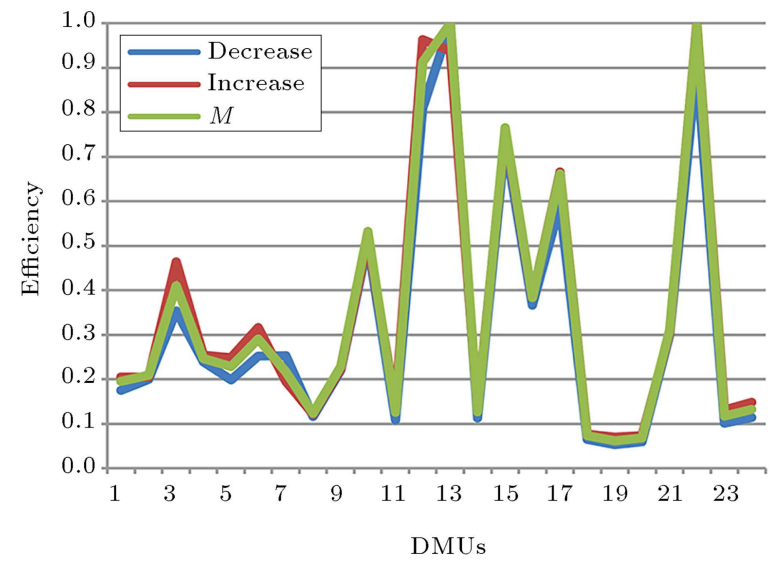

(c)

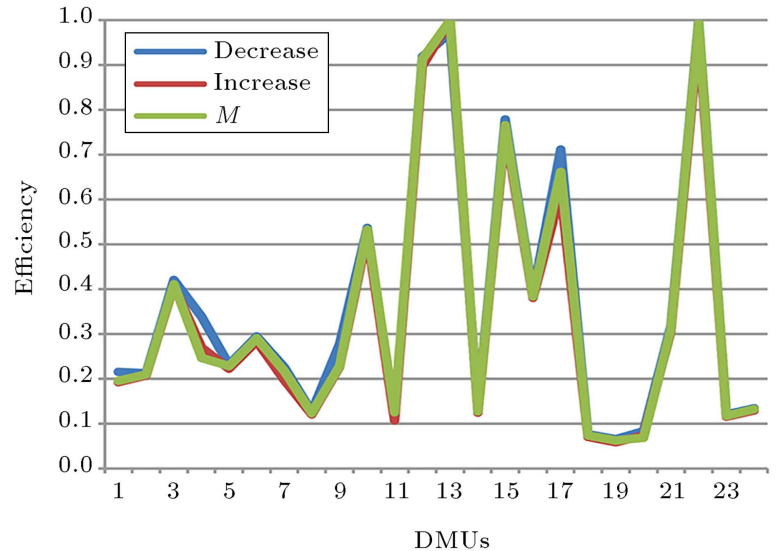

(b)

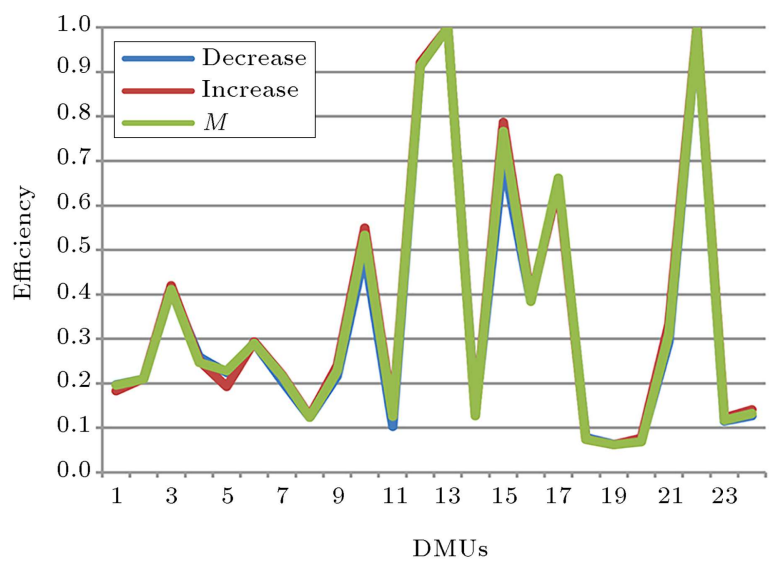

(d)

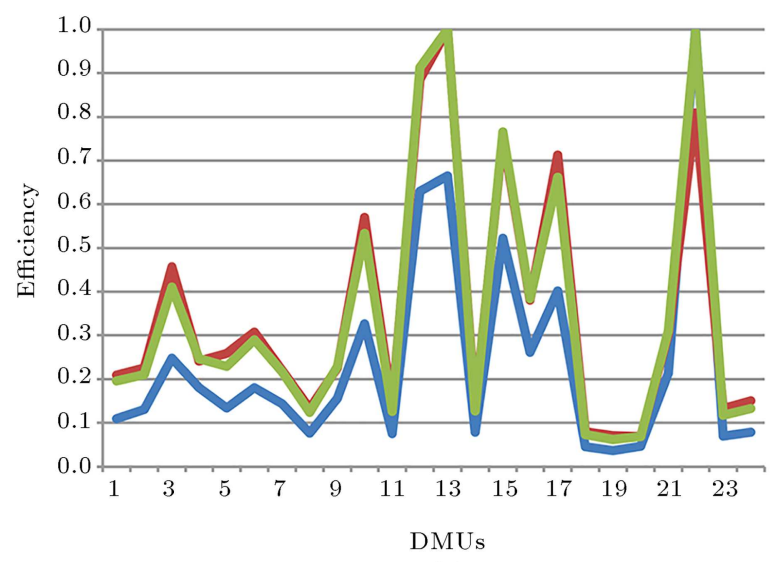

(e)

Figure 4. The results of sensitivity analysis on $I_{1}(\mathrm{a}), I_{2}(\mathrm{~b}), I_{3}$ (c), $I_{4}$ (d), and $I_{5}$ (e) indicators.

indicators had greater impact on the total profit $\left(O_{1}\right)$, utilization rate of machine capacity $\left(\mathrm{O}_{2}\right)$, and cost of reworking defective products $\left(\mathrm{O}_{3}\right)$ indicators than the maximum machine capacity and maximum labor level indicators. In this section, based on the number of changes and initial values for the objective functions (output indicators), appropriate decisions should be made. For example, the amount of the total profit $\left(O_{1}\right)$ and utilization rate of machine capacity $\left(O_{2}\right)$ for
DMU 22 increased upon increasing $I_{1}$ and $I_{5}$ indicators. By reducing $I_{1}$ and $I_{5}$ indicators and increasing $I_{3}$ indicator, a decrease in amount of the cost of reworking defective products $\left(\mathrm{O}_{3}\right)$ was observed.

The results indicated that the proposed algorithm had a high degree of accuracy and capability to assess the performance and could help managers make better decisions to improve efficiency and reduce waste of resources. The suggestion for future research is to use 
the effects of inflation and time value of money on the APP problems.

\section{References}

1. Rahmani, D., Yousefli, A., and Ramezanian, R. "A new robust fuzzy approach for aggregate production planning", Scientia Iranica, Transaction E, Industrial Engineering, 21(6), pp. 2307-2314 (2014).

2. Ramyar, M., Mehdizadeh, E., and Hadji Molana S.M. "Optimizing reliability and cost of system for aggregate production planning in supply chain", Scientia Iranica, 24(6), pp. 3394-3408 (2017).

3. Du, J., Liang, L., Chen, Y., and Bi, G.B. "DEAbased production planning", Omega, 38(1), pp. 105112 (2010).

4. Amirteimoori, A. and Kordrostami, S. "Production planning in data envelopment analysis", International Journal of Production Economics, 140(1), pp. 212-218 (2012).

5. Xiong, Y., Li, Z., and Fang, X. "Performance evaluation of introducing group technology into machining industry with data envelopment analysis", Journal of Interdisciplinary Mathematics, 20(1), pp. 295-305 (2017).

6. Kianfar, K., Ahadzadeh Namin, M., Alam Tabriz, A., Najafi, E., and Hosseinzadeh Lotfi, F. "Hybrid cluster and data envelopment analysis with interval data", Scientia Iranica, 25(5), pp. 2904-2911 (2018).

7. Khalili, J. and Alinezhad, A. "Performance evaluation in green supply chain using BSC, DEA and data mining", International Journal of Supply and Operations Management, 5(2), pp. 182-191 (2018).

8. Amini, A. and Alinezhad, A. "Integrating DEA and group AHP for efficiency evaluation and the identification of the most efficient DMU", International Journal of Supply and Operations Management, 4(4), pp. 318327 (2017).

9. Alinezhad, A., Sarrafha, K., and Amini, A. "Sensitivity analysis of SAW technique: The impact of changing the decision making matrix elements on the final ranking of alternatives", Iranian Journal of Operations Research, 5, pp. 82-94 (2014).

10. Mula, J., Poler. R., Garcia-Sabater, J.P., and Lario, F.C. "Models for production planning under uncertainty: A review", International Journal of Production Economics, 103, pp. 271-285 (2006).

11. Tang, J., Wang, D., and Fung, R.Y. "Fuzzy formulation for multi-product aggregate production planning", Production Planning \& Control, 11(7), pp. 670-676 (2000).

12. Wang, R.C. and Liang, T.F. "Aggregate production planning with multiple fuzzy goals", The International Journal of Advanced Manufacturing Technology, 25(5), pp. 589-597 (2005).
13. Tang, J., Fung, R.Y., and Yung, K.L. "Fuzzy modelling and simulation for aggregate production planning", International Journal of Systems Science, 34(12-13), pp. 661-673 (2003).

14. Aliev, R.A., Fazlollahi, B., Guirimov, B.G., and Aliev, R.R. "Fuzzy-genetic approach to aggregate production-distribution planning in supply chain management", Information Sciences, 177(20), pp. 42414255 (2007).

15. Jamalnia, A. and Soukhakian, M.A. "A hybrid fuzzy goal programming approach with different goal priorities to aggregate production planning", Computers \& Industrial Engineering, 56(4), pp. 1474-1486 (2009).

16. Yaghin, R.G., Torabi, S.A., and Ghomi, S.F. "Integrated markdown pricing and aggregate production planning in a two echelon supply chain: A hybrid fuzzy multiple objective approach", Applied Mathematical Modelling, 36(12), pp. 6011-6030 (2012).

17. Sadeghi, M., Hajiagha, S.H.R., and Hashemi, S.S. "A fuzzy grey goal programming approach for aggregate production planning", The International Journal of Advanced Manufacturing Technology, 64(9-12), pp. 1715-1727 (2013).

18. Gholamian, N., Mahdavi, I., Tavakkoli-Moghaddam, R., and Mahdavi-Amiri, N. "Comprehensive fuzzy multi-objective multi-product multi-site aggregate production planning decisions in a supply chain under uncertainty", Applied soft computing, 37, pp. 585-607 (2015).

19. Mosadegh, H., Khakbazan, E., Salmasnia, A., and Mokhtari, H. "A fuzzy multi-objective goal programming model for solving an aggregate production planning problem with uncertainty", International Journal of Information and Decision Sciences, 9(2), pp. 97-115 (2017).

20. Opricovic, S. and Tzeng, G.H. "Comparing DEA and MCDM method", Multi-Objective Programming and Goal-Programming: Theory and Applications, pp. 227232 (2003).

21. Raju, K.S. and Kumar, D.N. "Ranking irrigation planning alternatives using data envelopment analysis", Water Resources Management, 20(4), pp. 553-566 (2006).

22. Xiong, G. "The entropy DEA model and empirical analysis for measuring efficiency of industrial pollution control", In 4th International Conference on Wireless Communications, Networking and Mobile Computing, November 18, China (2008).

23. Shakouri, H., Nabaee, M., and Aliakbarisani, S. "A quantitative discussion on the assessment of power supply technologies: DEA (data envelopment analysis) and SAW (simple additive weighting) as complementary methods for the "Grammar"", Energy, 64, pp. 640-647 (2014).

24. Kuo, R.J. and Lin, Y.J. "Supplier selection using analytic network process and data envelopment analysis", International Journal of Production Research, 50(11), pp. 2852-2863 (2012). 
25. Mansouri, A., Naser, E., and Ramazani, M. "Ranking of companies based on TOPSIS-DEA approach methods (case study of cement industry in Tehran stock exchange)", Pak. J. Stat. Oper. Res., 10, pp. 189-204 (2014).

26. Saad, G.H. "An overview of production planning models: structural classification and empirical assessment", The International Journal of Production Research, 20(1), pp. 105-114 (1982).

27. Zimmermann, H.J. "Fuzzy programming and linear programming with several objective functions", Fuzzy Sets and Systems, 1(1), pp. 45-55 (1978).

28. Leung, S.C. and Chan, S.S. "A goal programming model for aggregate production planning with resource utilization constraint", Computers \& Industrial Engineering, 56(3), pp. 1053-1064 (2009).

29. Kersuliene, V., Zavadskas, E.K., and Turskis, Z. "Selection of rational dispute resolution method by applying new step-wise weight assessment ratio analysis (SWARA)", Journal of Business Economics and Management, 11(2), pp. 243-258 (2010).

30. Farahmand, M. and Desa, M.I. "RED: a new method for performance ranking of large decision making units", Soft Computing, 21(5), pp. 1271-1290 (2017).

\section{Biographies}

Javad Khalili obtained MSc degree in Industrial Engineering from Islamic Azad University of Qazvin. He received his BSc degree in the field of Industry Engineering - Industrial Production in 2012 and his MSc degree in the field of Industrial Engineering, System Management and Productivity from Islamic Azad University of Qazvin, Iran in 2017. His thesis is entitled "Performance evaluation in aggregate production planning by integrated approach of DEA and MADM under uncertain condition". His research interests are Multiple Criteria Decision Making (MCDM), Data Envelopment Analysis (DEA), Supply Chain Management (SCM), and production planning.

Alireza Alinezhad received his BSc degree in Applied Mathematics from Iran University of Science and Technology, MSc degree in Industrial Engineering from Tarbiat Modarres University, and PhD degree in Industrial Engineering from Islamic Azad University, Science and Research Branch. He is currently an Associate Professor at the Department of Industrial Engineering, Qazvin branch, Islamic Azad University, Qazvin, Iran. His research interests are Data Envelopment Analysis (DEA), Multiple Criteria Decision Making (MCDM), and quality engineering and management. 